\title{
EL DERECHO CONTABLE EN COLOMBIA
}

\section{ACCOUNTING LAW IN COLOMBIA}

Dra. Anayibe Ome Barahona ${ }^{\text {a }}$

${ }^{\text {a }}$ Universidad de la Amazonia

Facultad de Ciencias Contables, Económicas y Administrativas, a.ome@udla.edu.co

\section{RESUMEN}

El presente artículo tiene por finalidad, de una parte, dar a conocer el desarrollado del Derecho contable en Colombia, propiciado por las primeras regulaciones de tipo contable y comercial, expedidas con mucha antelación a la actual Constitución Política de 1991, que en su carácter de Texto Jurídico- Político, reconoce la importancia tanto de la contabilidad como de la profesión dentro del acontecer económico nacional; legitimidad que discrepa con lo preceptuado por la Ley 43 de 1990, reguladora de la profesión de contador público y compiladora del código de ética de la profesión contable, que presenta problemas de obsolescencia frente a los avances de la disciplina; cuestión que ha llevado a plantear su pronta modificación.

Y de otra, mostrar que el acervo legislativo colombiano de índole tributario suele superponerse a las normas contables; de ahí que la investigación documental aquí desarrollada, también recoja el análisis algunos preceptos normativos que, a efectos mercantiles y fiscales, consagran la obligación de llevar contabilidad y de facturar. De igual forma, se pudo constatar que existe abundante bibliografía sobre los fundamentos epistemológicos y teóricos de la contabilidad, que contrasta con la escasa literatura en materia jurídico-contable, lo que constituyó la principal cortapisa para robustecer el tema del Derecho contable colombiano.

PALABRAS CLAVE: Constitución; Derecho; Contabilidad; Profesión Contable. 


\section{ABSTRACT}

The purpose of this article is, on the one hand, to publicize the development of accounting law in Colombia, promoted by the first accounting and commercial regulations issued well in advance of the current Political Constitution of 1991, which, in its capacity as a legal and political text, recognizes the importance of both accounting and the profession in the national economic context; legitimacy which is at variance with the provisions of Law 43 of 1990, regulating the profession of public accountant and compiling the code of ethics of the accounting profession, which presents problems of obsolescence in the face of the advances of the discipline; a question that has led to raise its prompt modification.

On the other hand, to show that the Colombian legislative acquis of a tax nature tends to overlap with accounting standards; hence, the documentary research developed here, also includes the analysis of some normative precepts that, for commercial and fiscal purposes, establish the obligation to keep accounts and invoice. Similarly, it was found that there is abundant literature on the epistemological and theoretical foundations of accounting, which contrasts with the scarce literature on legal matters-accounting, which was the main obstacle to strengthening the issue of Colombian accounting law.

KEYWORD: Constitution; Law; Accounting; Accounting Profession.

\section{INTRODUCCIÓN}

La contabilidad surgió de la cotidianidad del hombre, que requirió contar y agrupar bienes de primera necesidad para su subsistencia. La cuantificación, desde entonces, hace parte de la naturaleza de la contabilidad, sin embargo, y dadas las exigencias y condiciones del mundo moderno, ha transcendido en la cualificación de la información que ha tomado importancia en estos tiempos de internalización de los negocios y de globalización del conocimiento.

Sin pretender que este artículo sea un trabajo filosófico del Derecho contable, aquí se esbozan cuestiones concretas de esta joven rama que viene tomando fuerza en otros 
ordenamientos, incluyendo el español, donde encontramos los primeros aportes en esta especialidad de las ciencias jurídicas, influenciados por el Derecho comunitario y las normas internacionales de información financiera y contable (Socías, 1992, p.47), que buscan su aplicabilidad por todo el empresariado, indistintamente del país de origen de las organizaciones económicas.

En el ordenamiento colombiano, la contabilidad ha sido objeto de constante regulación tanto a nivel de procesos como a título de la profesión contable. Esta normalización ha exhortado al gremio de los contadores públicos a permanecer a la vanguardia de los cambios que suceden en materia fiscal, de normas internacionales, de operación de los negocios y en medio ambiente, un nuevo campo de acción de la contabilidad, que se ha beneficiado de grandes aportes de las ciencias contables.

El artículo inicia con una breve revisión de la historia contable y de los antecedentes de la investigación en contabilidad, tanto a escala internacional como en el ámbito colombiano, como aspecto previo a la fundamentación teórica del Derecho contable que abre paso a las primeras regulaciones contables en Colombia y a la constitucionalización de la contabilidad y de la profesión contable, es este país suramericano.

Posteriormente, se enfatiza sobre la regulación contable que apareció en paralelo a la Constitución Política de 1991, y en la obligación jurídica de llevar contabilidad, que impone el Código de Comercio y la legislación tributaria. Luego se expone el rol de la contabilidad en la época de la globalización, acontecimiento que motivó el acondicionamiento de la factura de venta a título valor y a emitirla de forma electrónica, para más seguridad y confiabilidad de las operaciones que a través de ella se pactan.

El artículo finaliza con la relación de los aspectos de la Ley 43 de 1990, reglamentaria de la profesión de Contador Público, que serán objeto de la modificación próximamente. La Ley en cuestión se quedó corta respecto a los avances y novedades que trajo consigo los estándares internacionales de contabilidad adoptados en el ordenamiento colombiano, así como los avatares de la economía mundial, nacional y local. 


\section{Metodología}

El presente estudio trata de una investigación documental, con un enfoque descriptivo analítico, producto de la revisión normativa (Constitución, leyes contables, tributarias y comerciales, así mismo, decretos reglamentarios), y de la búsqueda y selección de información en diversas fuentes electrónicas de sustento jurídico-contable, ubicadas mediante la introducción de palabras claves, como: Derecho contable, la contabilidad desde la óptica jurídica, fundamentos epistemológicos de la contabilidad, la contabilidad como ciencia y técnica, rol de la contabilidad en la economía colombiana, la contabilidad dentro de la globalización económica, etc., en el buscador Google Scholar y en la base científica Dialnet.

\section{UNA MIRADA A LA HISTORIA CONTABLE Y A ANTECEDENTES DE LA INVESTIGACIÓN EN CONTABILIDAD}

\section{1 A escala internacional}

La contabilidad es tan antigua como la humanidad misma. Surgió en el "momento en que el hombre tuvo la necesidad de contar y anotar" (Casanal \& Virolia, 2007, p. 20), más exactamente en el periodo Paleolítico, época en que se empezó a utilizar unos objetos denominados "tokens", diseñados en forma de animales, granos, etc.; que se cree tenían por destinación la acción de contabilizar (Rosa, 2008, p.8); forjando, así, los primeros pinitos del sistema contable por partida simple.

El arcaico sistema de contabilizar cambió cuando "se perfeccionó la propiedad y el comercio" (Casanal \& Viloria, 2007, p.20). La propiedad privada y la actividad mercantil, que comprenden un derecho y una libertad, respectivamente, son más que un mutuo complemento, por cuanto, el uno da lugar al otro. El ejercicio mercantil se concreta en propiedad a raíz las utilidades o beneficios que arroja el negocio, por cuanto, el "fenómeno patrimonial [se comporta] como acumulador de riqueza" (Avellaneda \& Ortiz, 2012, p.263). 
La propiedad y la actividad mercantil dieron fuerza a la contabilidad como técnica, cuando se requirió registrar y cuantificar las operaciones que fueron apareciendo. Luego, la técnica de registrar cuentas, resultó "enriquecida por el desarrollo de la vida social, las organizaciones colectivas, y en suma, por las propias comunidades políticas primitivas" (Martín \& Veiga, 1998, p. 395).

La evolución contable, sin duda, la acentúo la partida doble surgida en el S. XIII, y formalizada por Fray Luca Bartolomeo de Pacioli (1447-1517), a través de su obra Tractatus Particularis de Computis et Scripturis (Hernández, 2006, p.93), que dio un giro a la contabilidad tradicional. Este método fue valioso para obtener "información detallada y (...) [ejercer] control global del negocio" (Villaluenga, 2013, p.129). El propietario, a partir de los libros Diario y Mayor propuestos por Pacioli, puede seguir de cerca el comportamiento y desarrollo de su actividad, gracias a que puede obtener un balance de su situación patrimonial.

En España se viene hablando de la contabilidad triangular o de partida triple, un complemento a la actual contabilidad, y aunque, su gestor Arjona (2013a, p. 3), advierte que no es un nuevo sistema contable ni se trata de una forma distinta de contabilizar, asegura que el método es bastante útil por los flujos de efectivo que nacen en el mismo asiento. Esta innovación, gracias a que incorpora cuentas de flujos de efectivo, es una oportunidad para rendir información contable más cualitativa y detallada a los usuarios de la misma (Arjona, 2013b, p. 10).

\section{2 En el ámbito nacional y local}

En el siglo pasado, hubo escasa investigación en materia contable, los profesionales se dedicaron más a la teneduría de libros, que a generar nuevo conocimiento; es decir que su actuación estuvo más inclinada en lo antológico y en lo praxiológico, dejaron de lado la representación ontológica y metodológica que debe predominar en este campo del saber (Machado, 2006, pp. 167 y 171). Aspecto marcado por "la falta de experiencia de los 
profesores y la falta de ciertas herramientas metodológicas. Esto hizo (...) [retrasar] los avances de investigación" (Pinzón-Pinto, 2011, p. 371).

El reducido número de profesionales en el campo de las ciencias contables, sobre todo en décadas anteriores a los años 70’s del siglo pasado, época en que - incluso - la legitimación de la práctica contable estuvo surcada de toda clase de dificultades (Benjumea, Camargo \& Roncancio, 2011, p. 19), truncó de cierta forma la investigación en contabilidad, los pocos conocedores del tema se empleaban en desarrollar la técnica contable, por lo que, la teoría tuvo que esperar.

Durante las últimas tres décadas del segundo milenio, en ocasión a la apertura de programas universitarios en el área contable, un grupo de contadores empíricos que ejercían como contabilistas en el sector comercio, obtuvieron formación profesional. Universidades como la Surcolombiana, que inició labores en calidad de Instituto Tecnológico, en 1971 empezó a ofertar la Tecnología en Contabilidad y Presupuesto, que entregó la primera promoción de egresados en el municipio de Florencia - Caquetá. En 1975, la tecnología cambió de modalidad y se transformó en el programa de Contaduría Pública.

La oferta académica de los programas de Contaduría Pública en Colombia ha ido en aumento, al punto que en 2010, estudios registran 1.674.420 de personas tituladas como contadores públicos en todo el territorio nacional (Uniamazonia, 2011, p. 20). Pese al número importante de profesionales en las ciencias contables, la investigación en esta área del conocimiento continúa siendo exigua; a ello se suman dificultades como el actual solapamiento sobre la contabilidad de las ciencias jurídicas y, desde un tiempo atrás, de las ciencias económicas y administrativas, que hasta ahora privan la posibilidad de considerarla una ciencia autónoma e independiente en un sentido riguroso de esta concepción (Mejía, Montes \& Mora, 2013a, p.65).

Frente al anterior panorama, la contabilidad en Colombia se ha caracterizado por ser más un proceso técnico que epistemológico. La contabilidad, aunque es la encargada de registrar y procesar la información económica, financiera, ambiental y social del ente comercial, no 
se tiene claro qué es: algunos la defienden como ciencia, otros aseguran que se trata de un arte o de una técnica, hay quienes aseveran, por el contrario, que se trata de una simple disciplina, y los más dogmáticos la consideran un sistema de información (Tocarema, 2016, p.4). Este último, enmarcado dentro de las ciencias sociales, cuyo fundamentos epistemológicos asociados a principios, leyes, métodos e hipótesis, juegan un papel preponderante en el desarrollo de las competencias propias del profesional de la contaduría pública (Torres \& Lam, 2012, p.32 ).

Así las cosas, se tienen posturas variadas sobre la contabilidad, la opinión no debería estar tan fraccionada, toda vez que, estamos ante "un saber dinámico, en constante movimiento en sus estructuras internas y en su relación externa con su objeto formal de estudio: la valoración cualitativa y cuantitativa (...) de la riqueza ambiental, social y económica (...)" (Mejía, Mora \& Montes, 2013b, p. 160), y de otros objetos que al día de hoy cuentan como el factor intelectual.

\section{3 Fundamentación teórica del Derecho contable}

La historia registra regulaciones en materia contable desde la época colonial, cuando se introdujo el modelo veneciano a nuestro territorio latinoamericano, a raíz de los avances aportados por Luca Paciolo, en el S. XV, y al desarrollo - en mediana potencia - de la actividad mercantil. Estas primeras regulaciones bien podían constituir el punto de partida del Derecho contable en Colombia; no obstante, esta rama se reconoce en nuestro ordenamiento a partir de los preceptos constitucionales, y al desarrollo de esos mandatos mediante leyes, decretos, resoluciones, conceptos doctrinales y jurisprudencia en materia contable, mercantil y económica.

Existen autores que, por el contrario, asocian el nacimiento de la nueva rama jurídica a los efectos propios de las ciencias jurídicas, que empieza con la "técnica especial de una actividad material, (...) [que transcurre] en el plano de la voluntariedad (...). Sin embargo, progresivamente, se les ha ido tiñendo de obligatoriedad, lo que implica el reconocimiento de consecuencias jurídicas concretas" (Durán \& Mejía, 2015, p.28). La conjugación de las 
dos circunstancias jurídicas, en todo caso, han favorecido el surgimiento del Derecho contable.

En ese orden de ideas, se descarta que la existencia de la especialidad del Derecho contable obedezca a la categoría probatoria de los estados financieros, que en Colombia adquirieron tras la declaratoria de la contabilidad como medio de prueba; no obstante, este gesto del legislador constituyente ha ayudado a enriquecer y fortalecer la concepción de la joven rama.

En los ordenamientos europeos se observa el desarrollo del Derecho contable, una dualidad desarrollada en ocasión a las "relaciones interdisciplinarias entre el Derecho, en cuanto Ciencia Jurídica, y la Contabilidad, en sus aspectos científicos y técnicos (...)" (Favier 2010, p. 11). Esta interdisciplinariedad ha ayudado a enriquecer los contenidos epistemológicos de las ciencias contables, asimismo, a formular nuevas y mejores pautas al aparato corporativo de las organizaciones.

En el ordenamiento español, el profesor Fernández (1985, p. 24), acuñó por primera vez el concepto de Derecho contable, reconociendo que el Derecho en su concepción jurídica, ha sido capaz de ordenar manifestaciones propias de las relaciones sociales, que luego se concretan en el hecho contable, como ocurre con el factor económico. La doctrina jurídica, de ahí en adelante, la legitimó como una especialidad del Derecho, precisamente por "la importancia que ha ido adquiriendo el hecho contable en las sociedades modernas, lo cual ha supuesto su regulación por el Derecho, dado el fuerte significado social alcanzado" (Socías, 1992, p.47).

En suma, el Derecho en su carácter normativo y regulatorio de las conductas humanas (Escobar, 2017, p.63), ha permeado la actividad contable y, aunque las normas que lo contienen se ciñen a prescribir comportamientos, en sí no expresan un significado representativo, contrario a los enunciados descritos en dichas normas, que sí lo manifiestan claramente (López, 2004, p. 317). La conducta humana que puede ser de tipo religioso, moral, convencional y jurídica (Montilla, 1956, p. 74), constituye el elemento determinante 
de la connotación de Derecho (Castaño., 2011, p.1), a ella obedece su surgimiento y desarrollo, así como el de las ciencias jurídicas.

\section{4 Primeras regulaciones contables en Colombia}

Resulta conveniente hacer remembranza desde la expedición del Código Mercantil, que recogió la Ley 57 de 1887, de 15 de abril, cuyo Artículo primero unificó el Código Terrestre Mercantil de 1869 y el Código de Comercio Marítimo de 1884; por cuanto, cobra importancia que a la luz de este cuerpo legislativo la contabilidad adquiere la categoría de medio probatorio, cuando la citada Ley 57 establece que quien incumpla el deber de contabilizar las operaciones de su negocio, además de ser sancionado con una multa, su contabilidad solamente se admitirá como medio de prueba, siempre y cuando, los libros contables se lleven conforme la ley (Puyo, 2016, p. 10).

A nivel de la profesión contable, el ya derogado Decreto 2373 de 1953, la reglamentó por primera vez; y en 1960, con expedición de la Ley 145, la práctica contable alcanza la categoría de profesión universitaria, quedando atrás el ejercicio empírico que venía reinando. La citada Ley 145, entró a definir la figura de contador público y concede facultades para otorgar fe pública en los documentos que el profesional llegase a firmar, en la medida que acreditase su titulación o autorización para ejercer la profesión. Más tarde, cerca de dos décadas y media, se sanciona la Ley 43 de 1990, que expresamente recoge aspectos relacionados con el ejercicio, vigilancia, dirección, control, relación sociedadEstado y aspectos éticos de la profesión de contador público (Uniamazonia, 2011, p. 9).

\section{5 Constitucionalización de la contabilidad y de la profesión contable}

La Carta Política de 1991, (CP, en lo sucesivo) le otorga rango constitucional al ejercicio de la profesión contable, con la consagración de la figura del Contador General de la Nación (Art. 354) que da lugar al nacimiento de la contabilidad pública, y con el reconocimiento de la contabilidad como medio de prueba en la medida que los libros, así como sus documentos soportes, serán tomados como elementos probatorios dentro de los procesos

Ome A.

El derecho contable en Colombia 
judiciales y en vía administrativa por las actuaciones tributarias, asimismo, en los casos de inspección, vigilancia e intervención a cargo del Estado, según lo establece el Art. 15 del Texto Fundamental.

Los libros y papeles de comercio que son la misma contabilidad en su integridad: libros, registros contables, inventarios y estados financieros en general (Art. 48 Código de Comercio), tienen eficacia probatoria siempre que sean llevados en debida forma; eso quiere decir que "una contabilidad que no satisfaga las exigencias legales o no lleve los libros indicados por la ley no puede considerarse fidedigna y, por tanto, no puede constituir prueba de lo que en ella se consigna", ha dicho la Corte Constitucional en su Sentencia C062 de 30 de enero de 2008.

\section{6 Regulación contable posterior a la Constitución Política de 1991}

Luego de la anterior declaratoria constitucional, en 1993, el Gobierno Nacional promulga el Decreto 2649, para reglamentar la contabilidad en general y formular los principios y normas contables de aplicabilidad en el sector empresarial, asimismo, el Decreto 2650 que establece el plan único de cuentas para comerciantes. Dos años después, el legislador ordinario, a través de la Ley 222 de 1995, incorpora varios elementos relacionados con el ejercicio de la profesión contable, entre ellos, la obligación del contador público de certificar los estados financieros preparados por él, antes de ponerlos a disposición de los grupos de interés (Art. 37); y le deja por función, elaborar notas explicativas a los mismos, para que tanto estados financieros como notas explicativas, conformen un todo indivisible (Art.36).

Antes de la CP, existían incipientes avances en el campo de la contabilidad pública. Los establecimientos oficiales o del orden estatal rendían información básica de sus operaciones a los diferentes entes de control, en formatos prediseñados a esos efectos. Cuestión superada con la entrada en vigor de la Ley 298 de 1996, que al abordar aspectos técnicos, investigativos y procedimentales de la contabilidad pública, entró a desarrollar el artículo 354 de la CP. La proclamación constitucional que tuvo la contabilidad pública, imprimió un 
progreso significativo a las ciencias contables, por cuanto, antes solo se reconocía la contabilidad privada y ahora existe la contabilidad pública.

\section{7 La obligación jurídica de llevar contabilidad}

Los comerciantes, es decir, las personas naturales y jurídicas que ejerzan la actividad mercantil, conforme las operaciones o actos descritos en el Art. 20 del Código de Comercio (C.C., en lo sucesivo), tienen la obligación de conformar su contabilidad, libros, registros contables, inventarios y estados financieros en general (Art. 48, C.C.) de sus negocios e inscribir en el registro mercantil todos los actos, libros y documentos que la ley exija cumplir con esa formalidad (Art. 19, C.C.). En ese orden de ideas, todo aquel que clasifique como comerciante está obligado a llevar contabilidad.

A diferencia del Código de Comercio, la legislación tributaria sólo exige esta obligación formal a los responsables del IVA (sujetos pasivos jurídicos), que son los importadores, los comerciantes y quienes realicen actos similares (Art. 437 del Estatuto Tributario, E.T., en lo sucesivo), siempre que no sean personas naturales que ejerzan el comercio o sean artesanos, minoristas o detallistas, que clasifiquen como pequeños agricultores y ganaderos, o, bien, que presten servicios, siempre y cuando cumplan a cabalidad con las condiciones especificadas en el Parágrafo $3^{\circ}$. del Art. 437 E.T.

Así las cosas, las personas naturales que no tengan la obligación de recaudar y declarar el IVA, aunque sean comerciantes, la legislación tributaria no los sanciona por no llevar libros de contabilidad, basta con que registren las operaciones diarias del negocio en un libro fiscal (Art. 616 E.T.). Este aparente solapamiento normativo no significa que la legislación fiscal desautorice al Código Comercio, todo lo contrario, quienes desarrollen la actividad de comercio y no posean la calidad de responsables del IVA, deberán llevar - también contabilidad a efectos mercantiles y civiles.

Los libros, comprobantes y demás documentos contables y administrativos son objeto de inspección o fiscalización por parte de las autoridades tributarias, no obstante, esta facultad 
sólo puede ejercerse dentro del establecimiento de comercio. Así lo ordena el Art. 780 E.T., que establece como lugar de presentación de los libros de contabilidad, las oficinas o establecimientos del contribuyente obligado a llevarlos.

De todas formas, la no presentación de los libros de contabilidad será indicio que se toma en contra del contribuyente. "El contribuyente que no presente sus libros, comprobantes y demás documentos de contabilidad cuando la administración [tributaria] lo exija, no podrá invocarlos posteriormente como prueba en su favor y tal hecho se tendrá como indicio en su contra" (Art. 781 E.T.).

La tarea fiscalizadora regulada por el Art. 684 E.T., es una de las amplias facultades concedidas a las autoridades tributarias para asegurar el efectivo cumplimiento de las normas sustanciales; ejercicio que no recae sobre todo el universo de contribuyentes, sino sobre una muestra aleatoria, la fiscalización integral no es posible por el deficiente recurso humano y tecnológico al alcance de las Administración tributaria (De La Vega, 2013, p.22).

\section{8 Rol de la contabilidad en la época de la globalización}

Terminando el siglo pasado, a raíz del apogeo de la globalización económica, el legislador colombiano, a través de la Ley 550 de 1999, relativa a la reactivación y reestructuración de las empresas colombianas, puso de relieve la necesidad de armonizar las normas contables domésticas con los usos y reglas internacionales para garantizar la calidad, suficiencia y oportunidad de la información que resulta de interés para asociados y terceras personas (Art. 63).

La interdependencia desatada con el fenómeno de la globalización, que ya no es sólo un asunto de economía global, sino de expansión mundial de los mercados financieros, de los medios tecnológicos y del conocimiento en todos los campos, involucró la actividad contable que debe adaptarse a las transformaciones que viene experimentando el mundo moderno; esto ha forzado tanto a la ciencia como a la profesión, a ampliar sus horizontes, a 
no cerrarse a la internacionalización de los negocios y a cumplir con las exigencias de los usuarios de la información contable (Rodríguez, De Freitas \& Zaá, 2012, p.167).

En palabras de Talla (2014, p. 71), no se trata de proveer cualquier información contable, sino, una cuya interpretación sea uniforme para que los distintos organismos empresariales puedan compararla en otros ordenamientos, con la finalidad principal de tomar decisiones adecuadas y oportunas. En la medida que la contabilidad doméstica se apoye en normas comunes de reconocimiento global y facilite la comparabilidad de datos y cifras, se podrá hablar que la contabilidad cumple con los objetivos para los que fue ideada, concluye el autor.

La armonización que buscó la Ley 550 de 1999, no fue inmediata, tardó diez años en darse, cuando se promulgó la Ley 1314 de 2009, o de convergencia mundial para la estandarización de las normas contables de aplicabilidad por aquellos sujetos obligados a llevar contabilidad. Se encargó - en consecuencia - de regular los principios y normas de contabilidad e información financiera y de aseguramiento, pero dadas las novedades que introdujo, ente ellas, la clasificación de la contabilidad según el tamaño de la empresa (grande, pequeña y mediana), es un contenido normativo que de manera negativa "impacta los tres aspectos fundamentales de la formación contable: conceptual, institucional y disciplinar" (Avellaneda, 2010, p. 212).

El contenido normativo de la Ley 1314 de 2009, lo critican autores como Rueda (2010, p.153), que, pese a visualizar coherencia entre la realidad económica y la política del país con las reglas universales de contabilidad, piensa que el marco normativo limita el alcance de esa política interna y del sistema empresarial, por cuanto, toma la inversión extrajera como la mejor alternativa a la generación de crecimiento económico y social, cuando el sector productivo nacional es polo de desarrollo por excelencia. En su opinión, quedaron excluidos ejes temáticos como ese que debieron reglamentarse, de cara a demostrar la función social que se espera de la contabilidad. 


\section{9 La factura de venta como principal soporte contable y su elevación a título valor}

La factura de venta comprende el soporte contable más representativo y valioso dentro de los procesos de fiscalización tributaria y de auditoría de la información. Este documento es de carácter comercial, y contiene toda la información de una operación de esa índole, ya sea por la compraventa de un bien o por la prestación de un servicio. La factura como soporta costos e ingresos es objeto de regulación fiscal y de frecuentes transformaciones como documento contable.

Una de las regulaciones la recoge el E.T. (compilador de la normativa tributaria), que en su Art. 615 obliga a los comerciantes, a las personas que ejerzan profesiones liberales o presten servicios inherentes a ellas, o bien, que enajenen bienes producto de la actividad agrícola o ganadera, a expedir factura o documento equivalente, bajo los requisitos estipulados en el Art. 617 E.T. ídem.

La factura, además de ser un mecanismo para "identifica[r] la mercadería, su calidad, cantidad y precio, (...) constituye un título de crédito que incorpora la obligación de pagar cierta suma de dinero en el plazo determinado, y es perfectamente negociable en el tráfico" (Rengifo \& Nieto, 2009, p.17). De ahí que el Código de Comercio la tome como documento cambiario de compraventa y la eleve a título valor, a fin que el vendedor la libre y entregue o remita al comprador. Excepto cuando no corresponda a una venta efectiva de mercaderías entregadas real y materialmente al comprador, en cuyo caso no podrá librarse la factura cambiaria (Art.772).

Debido a la anterior proclamación del Código de Comercio, en 2008, el legislador ordinario, mediante la Ley 1231 de esa anualidad, complementó la normativa mercantil, unificando todas las facturas existentes, dejándolas únicamente con la denominación de factura de venta y elevándolas a título valor por las operaciones a crédito, para su negociación con aquellos sujetos especializados en la compra de cartera. A partir de la novedad que introdujo la Ley en alusión, los comerciantes pueden negociar sus cuentas por 
cobrar simplemente con el endoso de la factura de venta a crédito, sin que su cliente tenga la necesidad de autorizarlo. Medida que ayuda principalmente a los microempresarios que requieren apalancarse de sus ventas a créditos (Romero, Fajardo \& Vélez, 2010, pp. 210, 216), por cuanto, es una declaración verdadera y una representación de la realidad financiera y económica.

\section{II.10 La factura de venta y su modernización a consecuencia de la internacionalización de los negocios}

En ocasión a la importancia de la factura como documento soporte mercantil, contable y fiscal, incluso, en los actos civiles, ha sido objeto de regulación como factura electrónica. El legislador colombiano desde 1995 intentó formalizar la factura electrónica; pese a la omisión, manipulación y falsificación que se venía presentando con las facturas tradicionales de papel, fue sólo hasta la entrada en vigor de la Ley 1819 de 2016 (Art. 308), que la declaró como sistema de facturación válido en Colombia. Antes de esta promulgación, era simplemente un documento equivalente a la factura litográfica.

La realidad de la transnalización de los negocios también incentivó la legitimación de la factura electrónica. Las empresas extranjeras y nacionales "buscan expandir sus negocios de manera segura y eficaz, dentro de unos parámetros que sean lo más común en el intercambio comercial” (Peña, 2010. p.39). Esta innovación, ha permitido - también ejercer control tributario sobre los ingresos y costos que llevan a determinar el Impuesto sobre las Ventas - IVA y el Impuesto sobre la renta y complementarios IRC.

La Ley 2010 de 2019, dio como plazo perentorio el 1 de enero de 2020, para expedir y exigir la factura electrónica; no obstante, dada la coyuntura económica y social del país, este término se postergó hasta que finalmente la Resolución 042 de 2020, del 5 de mayo, relativa, entre otros, al desarrollo de los sistemas de facturación, dejó a las actividades bajo los códigos CIIU: 01, 77, 90, 461, 41. 52, como fecha máxima el 1 de noviembre de 2020, para facturar electrónicamente. 
El Art. 18 de la Ley 2010 de 2019 establece que la "factura electrónica sólo se entenderá expedida cuando sea validada y entregada al adquirente", y es procedente en caso de impuestos descontables, y costos y gastos deducibles, que deberán estar soportados con factura electrónica por lo menos en un 70\% en 2020, un 80\% en 2021 y el $90 \%$ en 2022. Establece, en consecuencia, el mismo artículo legislativo, que "los documentos equivalentes generados por máquinas registradoras con sistema POS no otorgan derecho a impuestos descontables en el impuesto sobre las ventas, ni a costos y deducciones en el impuesto sobre la renta y complementarios para el adquiriente". A raíz de este precepto, quien necesite acreditarlos a efectos fiscales, deberá exigir la factura electrónica.

El sistema de facturación electrónica, además de "soportar las transacciones de venta de bienes y/o servicios" (Celis, 2019, p. 23), inyecta diversos beneficios tanto al emisor de la misma, que puede hacerla valer como título valor, como para el fisco nacional, que tiene la posibilidad de ejercer mayor control sobre los ingresos gravados de los responsables del IVA. Este sistema, por consiguiente, conduce a paliar la evasión y la elusión fiscal, y, por ende, a la generación de un mayor recaudo tributario.

Este novedoso sistema de facturación también beneficiará a los profesionales contables, que tendrán más tiempo para dedicar al análisis de la información y a la investigación; además los exhorta a mantenerse a la vanguardia de los procesos tecnológicos y los temas en informática contable, al tiempo que se verán forzados a cambiar las prácticas tradicionales de realizar el trabajo en su campo (LAVERDE \& BAUTISTA, 2020, pp.115 y 116).

\section{11 Próxima modificación de la Ley 43 de 1990}

El Gobierno de Colombia ha manifestado la necesidad de modificar la Ley 43 de 1990, reglamentaria de la profesión de contador público y del código de ética de la profesión contable. Luego de la adopción de las NIIF y las NIC en el ordenamiento contable, resulta importante y necesario actualizar la normativa marco de esta noble profesión. Una de las actualizaciones a darse, está relacionada con la fe pública que otorga el contador, por cuanto, actualmente riñe con las normas internacionales de contabilidad, que basa algunos 
cálculos en supuestos, cuando la fe pública debe recaer sobre hechos reales. Esto ayudará además - a contar con una regulación ajustada a la realidad económica, financiera, social y ambiental del país.

A consecuencia de ese anuncio, a lo largo y ancho del territorio nacional, se conformaron varios comités regionales, en marco de la convocatoria realizada por el Consejo Técnico de la Contaduría Pública - CTCP, de cara a: i) realizar un diagnóstico sobre la Ley 43 de 1990, y la normativa reglamentaria, ii) analizar las actuales definiciones que contempla mencionada Ley, y proponer nuevos conceptos, iii) examinar el campo de acción del profesional contable, iv) revisar los principios fundamentales del ejercicio profesional, y v) evaluar el código de ética que actualmente recoge la Ley en cuestión, para formular nuevas propuestas. Permitir que sea el mismo gremio de contadores públicos, quienes propongan cambios a su propia profesión, constituye un buen gesto del Gobierno colombiano.

\section{CONCLUSIONES}

Las ciencias contables, que recogen una serie de conocimientos obtenidos de manera sistemática y estructurada, a partir de la observación y el razonamiento, que se traducen en experiencias y dan cabida a principios y leyes generales; resultan autónomas pese a que se asocian con las ciencias sociales. Autonomía ausente en la contabilidad en su calidad de actividad que registra y procesa información de tipo económico, financiero, ambiental, etc., está condicionada a otras disciplinas del saber, como la economía, la informática, las matemáticas y el Derecho.

De la lista de las anteriores disciplinas vale resaltar el Derecho, que ha permeado la mayoría de áreas en que se desenvuelve la contabilidad y, en muchas ocasiones, a efectos fiscales y tributarios se sobrepone a las normas que la reglamentan. Esto ha llevado a generar estados financieros e información contable, tendiente más a cumplir con las obligaciones formales y la sustancial de la tributación, que a la toma de decisiones empresariales. 
El Derecho contable no obedece - necesariamente - al surgimiento de una vasta normativa para regular las prácticas y procesos contables, surge tras la aplicación de una técnica especial que deriva de la materialización de una actividad $\mathrm{y}$, pese a estar nutrida de voluntariedad, progresivamente ha adquirido obligatoriedad, desprendiéndose de ello consecuencias jurídicas que deben ser atendidas. Tal como sucede con la factura, que no se limita a ser un simple soporte contable, justifica transacciones mercantiles y acredita ingresos y costos.

En marco del Derecho contable, el profesional de la contaduría debe ser altamente competencial en la interpretación y aplicación de leyes, decretos, resoluciones, conceptos, jurisprudencia, etc. Se requiere que tenga desarrolladas las competencias interpretativas, comunicativas y de análisis.

\section{REFERENCIAS}

Arjona, A. (2013a). Planteamiento de la contabilidad triangular o de partida triple, memorias XVII Congreso de la Asociación Española de Contabilidad y Administración - AECA, p. 3.

Arjona, A. (2013b). La tercera partida: Una nueva dimensión contable, Revista Cont4bl3, No. 48, p. 10.

Avellaneda, C. A. (2010). Factores de incidencia de la Ley 1314 de 2009 en la Educación Contable colombiana, Criterio Libre, Vol. 8, No. 12, Bogotá (Colombia), Enero - Junio 2010, p. 212.

Avellaneda, C. A. \& ORTIZ, J. J. (2012). Explicación contamétrica de las dinámicas patrimoniales desde una concepción social, Revista Criterio Libre, Vol. $10 \cdot$ No. $17 \cdot$ Bogotá (Colombia) - JulioDiciembre 2012, p. 263.

Benjumea, L. F., Camargo, D. A. \& Roncancio, A. D. ( 2011). Aproximaciones a la historia de la contabilidad en Colombia, Revista Estudiantes Facultad de Ciencias Económicas, Vol. 1, No. 1, p. 19.

Casanal, R. \& Virolia, N. (2007). La Ciencia Contable, su historia, filosofía, evolución y su producto, Revista Actualidad Contable Faces, Vol.10, No. 15, p. 20.

Castaño B. A. (2011). La conducta como elemento configurador en el concepto de Derecho. Su ámbito de aplicación como el primer analogado en la filosofía práctica, Revista Díkaion, Año 25 Vol. 20, No. 2, Chía, Colombia - Diciembre 2011, p.1. 
Celis, M. L. (2019). Implicaciones de la nueva regulación de la factura electrónica como título valor en Colombia, Trabajo de grado presentado como requisito para obtener el título de: Abogado, Universidad Externado de Colombia, p. 23.

De la Vega, B. (2013). La discrecionalidad de la Administración Tributaria y el procedimiento de fiscalización, XII Jornadas Nacionales de Derecho Tributario, p.22. Localizable en: https://www.ipdt.org/uploads/docs/01 Rev56 DeLaVega.pdf consultado el 15 de noviembre de 2020.

Durán, L. \& Mejía, M. (2015). El Derecho Contable Peruano, Revista Lidera, No. 10, p.28.

Escobar, C. (2017). El derecho como ciencia: una aproximación desde la epistemología sobre el carácter de cientificidad del derecho y su praxis, Tese de Doutoramento, Escola de Doutoramento Internacional, Programa de Doutoramento en Lóxica y Filosofía da Ciencia, p.63.

Favier, E. M. (2010). El derecho contable como nueva ciencia interdisciplinaria y autónoma, XI Congreso Argentino de Derecho Societario, VII Congreso Iberoamericano de Derecho Societario y de la Empresa (Mar del Plata), p. 11.

Fernández, J. Ma. (1985). Una aportación a la construcción del derecho contable, Memoria para optar el título de doctor en Derecho, Universidad Complutense de Madrid, p. 24.

Hernández, E. (2006). Reflexiones sobre la naturaleza y los orígenes de la contabilidad por partida doble, Revista de Contaduría Universidad de Antioquia, No. 49, p. 93.

Laverde, M. A. \& Bautista, J. A. (2020). Análisis de los cambios en la profesión contable tras el proceso de implementación de la 1facturación electrónica en Colombia, Revista CIFE, BogotáColombia, Vol. 22, N. ${ }^{o}$ 37, julio-diciembre 2020, pp.115 y 116.

López, J. (2004). El concepto de Derecho de Alf Ross en su etapa analítica, Anuario de Filosofía del Derecho, No. XXI, p. 317.

Machado, (2006). Una aproximación histórica a las representaciones contables en Colombia, Revista Española de Historia de la Contabilidad, No. 5, pp. 167 y 171.

Martín, P. B. \& Veiga Copo, A. B. (1998). Los libros de contabilidad: un apunte histórico, Boletín de la Facultad de Derecho, No. 13, p. 395.

Mejía, E.; Mora, G. \& Montes, C. A. (2013a). Identificación del objeto de estudio de la contabilidad, Revista Libre Empresa, Vol. 10, No. 1, Enero - Junio de 2013, p.65.

Mejía, E.; Mora, G. \& Montes, C. A. (2013b). Adscripción de la contabilidad en la estructura general del conocimiento, Cuadernos de Contabilidad, Bogotá - Colombia, Vol. 14, No. 34, enerojunio 2013, p. 160.

Montilla, B. (1956). Teoría Tridimensional del Derecho, Instituto Brasileiro de Filosofía, p. 74.

Peña, O. (2010). La factura de venta en Colombia, una breve mirada frente a la globalización, Revista Jurídicas CUC, No. 6, Barranquilla, Colombia, p.39. 
Pinzón, J. E. (2011). Historia de la contaduría pública en Colombia siglo XX: a 20 años de su publicación, Cuaderno Contable, Bogotá - Colombia, Vol. 12, No. 30, enero-junio 2011, p. 371.

Puyo, R. (2016). Aproximación a una historia del registro mercantil en Colombia, Revista de Derecho, Vol. 58, No. 1(90), Medellín - Colombia, p. 10.

Rengifo, R. \& Nieto, N. (2009). Facturas comerciales comentarios a la ley 1231 de 17 de julio de 2008, Vol. 66, No. 147, p.17.

Rodríguez, J. M., De Freitas, S. \& Zaá, J. R. (2012). La contabilidad en el contexto de la globalización y la revolución teleinformática, Revista Venezolana de Análisis de Coyuntura, vol. XVIII, núm. 1, enero-julio, 2012, p.167.

Romero, M. et al (2010). Aspectos jurídicos y tributarios de la factura como título valor, Revista Criterio Libre, Vol. 8, No. 13, Bogotá (Colombia), Julio-Diciembre 2010, pp. 210, 216.

Rosa, S. E. (2008). La contabilidad y el origen del hombre: Conjeturas sobre su trascendencia en el desarrollo y destino de la humanidad, III Jornadas Universitarias Internacionales de Contabilidad, p. $8 . \quad$ Localizable en: file:///C:/Users/DELL/Downloads/DialnetLaContabilidadYElOrigenDelHombre-2860350\%20(1).pdf Consultado el 27 de octubre de 2020.

Rueda, G. (2010). El papel de la contabilidad ante la actual realidad económica, social y política del país. Más allá de la convergencia de prácticas mundiales, cuadernos de Contabilidad, Bogotá Colombia, Vol. 11, No. 28, enero-junio 2010, p.153.

Socías, A. (1992). El Derecho contable en España, Cuadernos de la Facultad de Derecho (UIB), No. 18,1992, p.47.

Talla, S. (2014). La globalización y la armonización contable, Sistemas de Bibliotecas - SISBIB, Quipukamayoc, Facultad de Ciencias Contables, p. 71.

Tocarema, P. E. (2016). Perspectiva de la contabilidad, como ciencia, arte, técnica, disciplina, sistema de información bajo la óptica de las NIC y las NIIF, Universidad Militar Nueva Granada, Facultad de Educación a Distancia - FAEDIS, Programa de Contaduría Pública, p.4.

Torres, C. \& Lam, A. (2012). Los fundamentos epistemológicos de la contabilidad y su incidencia en la formación competitiva del contador público, Revista Sotavento M.B.A. No. 19, p.32.

Uniamazonia (2011). Condiciones mínimas de calidad para renovación de registro calificado del programa de Contaduría Pública, Facultad de Ciencias Contables, Económicas y Administrativas, Universidad de la Amazonia, Florencia, Caquetá - Colombia, pp. 9 y 20.

Villaluenga, S. (2013). La partida doble y el cargo y data como instrumentos de un sistema de información contable y responsabilidad jurídica integral, según se manifiesta en fuentes documentales de la Catedral de Toledo (1533-1613), Revista de Contabilidad - Spanish Accounting Review, No. 16, Vol. 2, p.129. 